Methodist DeBakey

\section{Cardiovascular Journal}

Volume 10, Number 3, 2014

ISSN 1947-6094

houstonmethodist.org/debakey-journal

\section{Editor-in-Chief}

William L. Winters Jr., M.D.

\section{Associate Editor for Medicine}

Stephen H. Little, M.D.

\section{Associate Editor for Surgery}

Michael J. Reardon, M.D.

\section{Guest Editors}

William A. Zoghbi, M.D.

\section{Managing Editor}

Susan Daniels, Ph.D.

\section{Copy Editor}

Shelley Barnes, B.A.

\section{Contributing Editor: Points to Remember} Juan Olivero, M.D.

\section{Contributing Editor: Dr. Phil's Art Corner} Philip Alexander, M.D.

\section{Contributing Editor: Poet's Pen}

Michael W. Lieberman, M.D., Ph.D.

\section{Editorial Board}

Michel Bertrand, M.D.

Lois DeBakey, Ph.D.

Joseph Naples, M.D.

Craig Pratt, M.D.

Michael Donovan, B.S.

Kim A. Eagle, M.D.

Miguel Quiñones, M.D.

Albert Raizner, M.D.

Robert A. Guyton, M.D. Michael J. Reardon, M.D.

Gerald Lawrie, M.D.

Frank J. Veith, M.D.

Alan B. Lumsden, M.D. James B. Young, M.D.

The Methodist DeBakey Cardiovascular Journal (MDCVJ) is published 4 times a year by Houston Methodist Hospital, Houston, Texas. The journal provides an update from Houston Methodist DeBakey Heart \& Vascular Center specialists about leadingedge research, diagnosis, and treatments as well as occasional articles or commentary

by others.

$M D C V J$ is written for physicians and should be relied upon for medical education purposes only. It does not provide a complete overview of the topics covered and should not replace the independent judgment of a physician about the appropriateness or risks of a procedure or treatment for a given patient.

U.S. News \& World Report ranks the Houston Methodist DeBakey Heart \& Vascular Center's cardiology, cardiothoracic and vascular surgery programs No. 12 in the nation.

(C) 2014 Houston Methodist Hospital Houston, Texas

\section{Houston Methodist DeBakey Heart \&}

\section{Vascular Center}

6565 Fannin Street, Houston, Texas 77030

Telephone: 713-DEBAKEY (713.332.2539)

houstonmethodist.org/debakey-journal

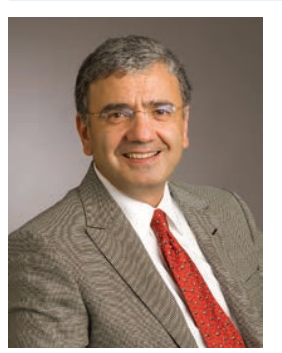

WILLIAM A. ZOGHBI, M.D., LENDS EXPERTISE ON SPECIAL IMAGING ISSUE OF THE METHODIST DEBAKEY CARDIOVASCULAR JOURNAL
The editors of the Methodist DeBakey Cardiovascular Journal extend a heartfelt thanks to William A. Zoghbi, M.D., for serving as guest editor of this special issue on multimodality cardiac imaging.

A leader in cardiology and cardiovascular imaging, Dr. Zoghbi is the William L. Winters Endowed Chair of Cardiovascular Imaging at the Houston Methodist DeBakey Heart \& Vascular Center in Houston Methodist Hospital and is director of the hospital's Cardiovascular Imaging Institute, which he founded in 2005. Dr. Zoghbi completed his internal medicine and cardiology training at Baylor College of Medicine in Houston, where he joined the faculty in 1985 and became the John S. Dunn Professor of Medicine and director of the echocardiography laboratory.

Dr. Zoghbi has developed novel techniques to evaluate valvular disorders and cardiac function, improving the noninvasive evaluation and management of heart disease. He is also known for his research on myocardial hibernation and his development of 3-dimensional techniques to evaluate valvular dynamics and measure valvular regurgitation. Dr. Zoghbi has authored more than 250 original publications and has been invited to lecture on his work at every major cardiology conference around the globe. He also has trained more than 100 cardiology fellows in advanced cardiovascular imaging, many of whom now hold positions of leadership in academic medicine. A recipient of the Richard Popp Excellence in Teaching Award from the American Society of Echocardiography (ASE), Dr. Zoghbi chaired the development of national and international guidelines for evaluating native and artificial heart valves with cardiac ultrasound, and he co-chaired the American College of Cardiology (ACC) committee that wrote a monograph on how best to train the new generation of cardiologists in multimodality cardiovascular imaging.

Dr. Zoghbi has been actively involved with the ACC, the American Heart Association, and the ASE for more than 25 years, serving as president of both the ASE and ACC and on the ACC's board of trustees since 2001. He is currently a board member of the World Heart Federation, co-chairing its Global Task Force for Cardiovascular Disease, and recently represented the ACC at the United Nations and World Health Organization. 